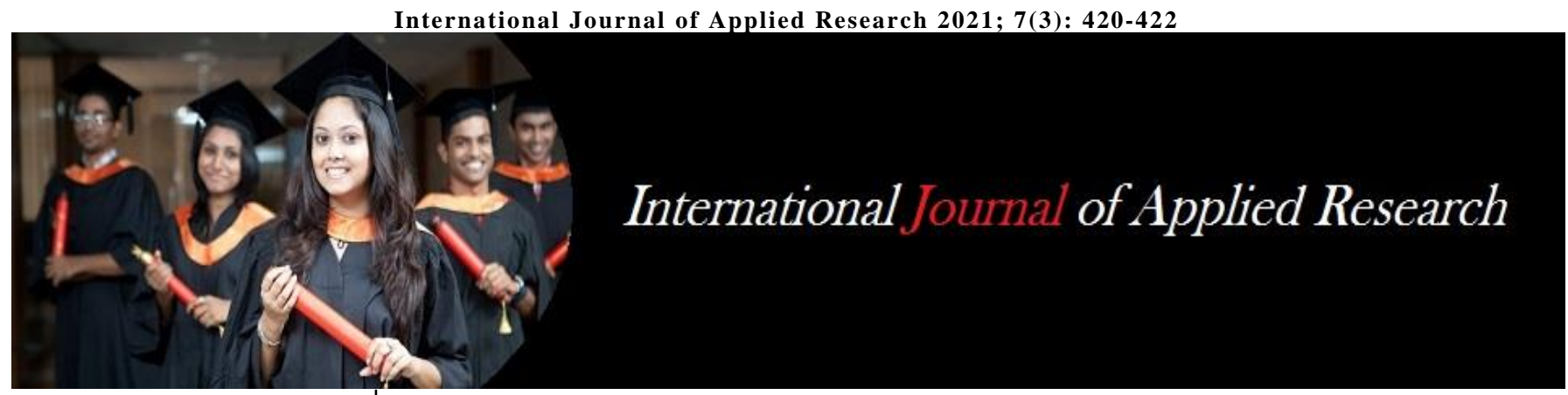

ISSN Print: 2394-7500 ISSN Online: 2394-5869 Impact Factor: 8.4 IJAR 2021; 7(3): 420-422 www.allresearchjournal.com Received: 13-01-2021 Accepted: 19-02-2021

Nazakat Manzoor

M.Sc Nursing, Community Health Nursing, Bharati Vidyapeeth (Deemed to be University) College of Nursing, Pune, Maharashtra, India

Vinata Jamdade Clinical Instructor, Community Health Nursing Bharati Vidyapeeth (Deemed to be University) College of Nursing, Pune, Maharashtra, India
Corresponding Author: Nazakat Manzoor M.Sc Nursing, Community Health Nursing, Bharati Vidyapeeth (Deemed to be University) College of Nursing, Pune, Maharashtra, India

\section{A study to assess the knowledge and attitude regarding depot medroxyprogesterone acetate (DMPA) contraceptive among couple from selected urban areas of Pune city}

\section{Nazakat Manzoor and Vinata Jamdade}

DOI: https://doi.org/10.22271/allresearch.2021.v7.i3g.8441

\section{Abstract}

Title: Assess the Knowledge and Attitude Regarding Depot Medroxyprogesterone Acetate (DMPA) Contraceptive Among Couple.

Objectives: Assess the knowledge and attitude regarding use of Depot Medroxyprogesterone acetate (DMPA) among couple.

Materials and Methods: A quantitative descriptive research design is used in this research study. A Non-Probability Purposive sampling technique was used. Total 80 samples were included in the study. Self-structured questionnaire was prepared to assess the knowledge and Likert scale was used to assess attitude regarding Depot Medroxyprogesterone acetate (DMPA). The collected data were analysed by using descriptive and inferential statistics and Chi- square test was used to associate the demographic variables with knowledge and attitude regarding.

Result: The findings revealed that, $51.3 \%$ belonged to the $26-30$ year of age group. $55 \%$ had completed Secondary education, 56.3\% participants were doing Private job, $70 \%$ were having 1 child. $70 \%$ participants were using condom, 91.3\% couple using contraceptive on regular basis. Majority $(56.25 \%)$, of the couples had an average knowledge, \&87.50\% of couples have Positive attitude towards Depot Medroxyprogesterone Acetate (DMPA) among couple in selected urban areas of Pune city.

Conclusion: In this study, majority of couple have Average knowledge and positive attitude regarding use of Depot Medroxyprogesterone acetate (DMPA) among couple. Thus, awareness is required to motivate more and more couple to use Depot Medroxyprogesterone Acetate (DMPA).

Keywords: parental attitude, participation, sports, girls

\section{Introduction}

Contraception is the method to prevent the unwanted Births among couples, it varies in its types like barrier methods, IUCDs, Injectable, chemicals etc. Among various different injectable contraceptives Depot Medroxyprogesterone acetate (DMPA) is the commonest type because it has been found to be very effective, long acting and reversible. This is similar to the hormone progesterone, which is naturally produced by the female body. It is given in a dose of $150 \mathrm{mg}$ intra-muscularly every three months. It works in many ways like by blocking LH surge and therefore prevents ovulation. It also thickens cervical mucus and alters the endometrial receptivity for implantation. It can be started anytime of the menstrual cycle, preferably within first 5 days of menstrual bleeding.

\section{Need of the study:}

A large group of population in Maharashtra are still unaware that injectable contraceptives especially Depot Medroxyprogesterone acetate (DMPA) is available free of cost in the government hospitals, district hospitals etc.

Also even if some of them know about this contraceptive they are unwilling to use it because they lack certain basic knowledge regarding the benefits of using this method like it does not interfere with sexual intercourse or it has very minimal side effects, it provides less pain to 
women, follow-up is required after 3 months, it has less failure rates, once the contraceptive is administered the couple needs not to worry for next 3 months and there is no chance of unwanted pregnancy for next 3 months ${ }^{[4]}$.

Thus, advice on Contraceptive is a vital component of good community health and it is our duty to assess the level of knowledge regarding injectable contraceptives among people because even if a person if highly qualified, he may lack the knowledge about this type of contraception. So this study will help us to identify about the level of knowledge regarding Depot Medroxyprogesterone acetate (DMPA) and attitude of couple towards use of Depot Medroxyprogesterone acetate (DMPA) which will in turn help us to identify the need of educating them about this method because it is assumed that couples have very less knowledge regarding Depot Medroxyprogesterone acetate (DMPA)as it was assessed by the researcher during her clinical posting at a government hospital that very less couple were coming to the hospital for administration of Depot Medroxyprogesterone acetate (DMPA), the no. of couple was only 2-5 during a month. Also, during her visit to family welfare bureau at Pune she went through the statistics of using Depot Medroxyprogesterone acetate (DMPA) in Pune and it was found that the no. of couple using this contraceptive was very low ${ }^{[5]}$.

\section{Objectives of the study:}

1. To assess the knowledge about use of Depot Medroxyprogesterone acetate (DMPA) among couple.

2. To assess the attitude about use of Depot Medroxyprogesterone acetate (DMPA) among couple.

3. To associate the findings with the selected demographic variables.

Methodology

Research Approach: A Quantitative Approach

Research Design: Non Experimental Design.

Research Settings: Community area of Pune city

Population: Couples from the Community area of Pune city.

Sample: A total of 80 sample was taken, most of them were females because they used to be at home during day time.

\section{Criteria for Sample Selection \\ Inclusion criteria}

- Willing to participate.

- Married males and females

\section{Exclusion Criteria}

- Females having breast cancer or family history of breast cancer

- $\quad$ Females having systemic disease.

\section{Sample Size:- 80}

Sampling Technique: Non-probability purposive sampling technique

Data Collection Tool consist of Personal characteristics of samples, assessment of knowledge and attitude about use of Depot Medroxyprogesterone acetate (DMPA) among couple, assessment of association of demographic data with knowledge and attitude about use of Depot Medroxyprogesterone acetate (DMPA) among couple

\section{Results}

Findings of sample characteristics

Study showed that among the participants, majority $51.3 \%$ belonged to the 26-30 year of age group, $45 \%$ belonged to the of 21-25 year of age group and 3.8\% participants were in the age group of 18-20years of age group.

Findings also depicts that Majority of participants 55\% had completed Secondary Education and $36.25 \%$ participants had completed Primary Education and $8.8 \%$ participants had Higher Education.

Regarding their occupation, $56.3 \%$ participants were doing Private job, $23.8 \%$ were unemployed, $15 \%$ were selfemployed, and $5 \%$ were doing Govt. Job

Further number of children majority of participants70\% were having 1 child, $12.5 \%$ participants were having 2 children, $11.3 \%$ participants having 0 child, and $6.3 \%$ participants were having more than 3 children.

Findings also shows that maximum $91.3 \%$ participants using contraceptive on regular basis, $5 \%$ had never used, and $3.8 \%$ had used only once till now.

\section{Findings related to assessment of knowledge about use of Depot Medroxyprogesterone acetate (DMPA) among couple}

Study revealed that majority of the couples had an average knowledge regarding the Medroxyprogesterone acetate (DMPA) i.e. $56.25 \%$, while only $11.25 \%$ had a good knowledge and $32.5 \%$ were having poor knowledge regarding the topic.

Findings related to assessment of the attitude about use of Depot Medroxyprogesterone acetate (DMPA) among couple

Study revealed that majority $70(87.50 \%)$ of couples have Positive attitude and $10(12.5 \%)$ have Negative attitude regarding use of Depot Medroxyprogesterone Acetate (DMPA) among couple in selected urban areas of Pune city.

Findings related to association of the findings with the selected demographic variables

Only four variables; Number of children, education, contraceptive used till now and occupation were calculated more than chi square table value so these four variables were associated with knowledge about use of Depot Medroxyprogesterone acetate (DMPA) among couples. Other variable Age and type of contraceptive use were calculated less than chi square table value so there is no association.

Similarly, Education, number of children, which contraceptive use and frequency of use till now were calculated more than chi square table value so these four variables were associated with attitude about use of Depot Medroxyprogesterone acetate (DMPA) among couples. Other variable Age and Occupation were calculated less than chi square table value so there is no association.

\section{Acknowledgement}

We will like to extend our sincere gratitude to all the participants for taking part in our study and making this study a success. We will also like to thank all the concerned 
authorities for granting us permission to conduct this research.

\section{Discussion}

The researcher had conducted a visit to the family welfare bureau, Pune. The objective of the visit was regarding family planning. The information revealed in the bureau was that Depot Medroxyprogesterone acetate (DMPA) was one of the effective methods of contraception which was made freely available but a larger segment of population needed awareness regarding the same. This lack of awareness among the general population led to conduction of research on the topic by the researcher in selected Urban areas of Pune city. The results revealed that an average number of populations were aware of the Depot Medroxyprogesterone acetate (DMPA) contraceptive and had a positive attitude about its use yet they didn't use it in their daily practices. The reason for lack of application wasn't covered under this research project however it could be found in many new researches to come.

\section{Conclusion}

The conclusion drawn out from the study revealed that as follows

The title of the study was "A study to assess the knowledge and attitude regarding Depot Medroxyprogesterone acetate (DMPA) contraceptive among couple from selected urban areas in Pune city". showed that majority of couple have Average knowledge and while some of the couple have poor knowledge and only a few have good knowledge regarding Depot Medroxyprogesterone acetate (DMPA) among couple. Study also showed that majority of couples have Positive attitude and only some have Negative attitude regarding use of Depot Medroxyprogesterone Acetate (DMPA) among couple in selected urban areas of Pune city. Chi Square test was used to find the association between of variables with selected demographic variables.

\section{References:}

1. Family_planning_in_India @ en.wikipedia.org.

2. $92 \mathrm{~b} 5 \mathrm{c} 45 \mathrm{a} 4 \mathrm{f} 2 \mathrm{e} 862 \mathrm{f529616d0204f750f46b580c5}$ @www.ncbi.nlm.nih.gov.

3. GOI. Family Planning services under Ministry of Health and Family planning. 2018;95-108.

4. population_explosion@www1bpt.bridgeport.edu.

5. View@Www.Open.Edu.

6. 139c11ab1ebb059e5f250830f1fbb29adfedc1ae @ systemsinnovation.io.

7. Health_belief_model @ en.wikipedia.org.

8. Navdeep kaur brar $\mathrm{H}$ rawat. A textbook of advanced nursing practice. ist. jaypee; 696-709 p.

9.6426380@www.ncbi.nlm.nih.gov.

10. 2559568bf5304d3b7e8cef7cf69b5fe1211e26c8 @ www.ncbi.nlm.nih.gov.

11. health_belief_model @ currentnursing.com.

12. 7532c6acb6a1377cef3541af7e53c8a961888482@ www.ncbi.nlm.nih.gov. 